\title{
BMJ Open Longitudinal body weight and sputum conversion in patients with tuberculosis, Southwest Ethiopia: a retrospective follow-up study
}

Mersha Filate, ${ }^{1}$ Zelalem Mehari, ${ }^{2}$ Yihun Mulugeta Alemu ${ }^{2}$

To cite: Filate M, Mehari Z, Alemu YM. Longitudinal body weight and sputum conversion in patients with tuberculosis, Southwest Ethiopia: a retrospective follow-up study. BMJ Open 2018;8:e019076. doi:10.1136/ bmjopen-2017-019076

- Prepublication history for this paper is available online. To view these files please visit the journal online (http://dx.doi org/10.1136/bmjopen-2017019076).

Received 14 August 2017

Revised 28 June 2018

Accepted 20 August 2018
Check for updates

(c) Author(s) (or their employer(s)) 2018. Re-use permitted under CC BY-NC. No commercial re-use. See rights and permissions. Published by BMJ.

${ }^{1}$ Department of Statistics, Jimma University, Jimma, Ethiopia

${ }^{2}$ Department of Epidemiology and Biostatistics, School of Public Health, College of Medicine and Health Sciences, Bahir Dar University, Bahir Dar Ethiopia

Correspondence to Yihun Mulugeta Alemu; yihun.mulugeta@yahoo.com

\section{ABSTRACT}

Objectives To describe the association between change in body weight and sputum smear conversion and to identify factors linked with body weight and sputum smear conversion in Jimma University Specialized Hospital, Southwest Ethiopia.

Design A retrospective follow-up study.

Setting Teaching hospital in Southwest Ethiopia.

Participants A total of 450 patients with tuberculosis (TB) were included in the follow-up between 2011 and 2013.

Main outcome measures The association between body weight and sputum conversion was measured using joint modelling.

Results The association between change in body weight and change in sputum conversion was $-0.698(p<0.001)$. A strong inverse association between change in body weight and change in sputum conversion was observed. The study variables sex, age, type of TB, HIV status, dose of anti-TB drug and length of enrolment to TB treatment were significantly associated with change in body weight of patients with TB. The study variables age, type of $T B$, dose of anti-TB drug and length of enrolment were significantly associated with change in sputum status of patients with TB.

Conclusions Among patients with TB who were on antiTB treatment, increase in body weight and positive sputum status were inversely related over time. TB prevention and control strategies should give emphasis on factors such as female sex, older age, non-pulmonary positive type of TB, HIV-positive, lower dose of anti-TB drug and length of enrolment to TB treatment during monitoring of trends in body weight and sputum status.

\section{BACKGROUND}

Tuberculosis (TB) remains the major cause of morbidity and mortality throughout the world. ${ }^{1}$ Patients with positive pulmonary TB are the most important segment of population with regard to controlling the spread of TB. Sputum conversion can be affected by the age of the patient, total number of administered anti-TB drugs, comorbidities (diabetes mellitus, HIV and cancer) and nutritional status. $^{2}$ Both underweight and overweight are pathologically linked to sputum conversion. ${ }^{3-6}$
Strengths and limitations of this study

Modelling the relationship between a survival endpoint and longitudinal outcomes improves the efficiency of health research and provides greater insight into the various dimensions of clinical outcomes of interventions.

- One of the limitations of joint modelling is calculation challenge, which requires to integrate the distributions of random effects even with fairly simple circumstances, that is, a single longitudinal outcome and a single survival event.

- As we conduct this retrospective follow-up study, predictors could not establish temporal relationship; therefore, causation of factors cannot be inferred.

Change in body weight of patients with TB significantly affects treatment outcomes. Patients who lose body weight in the first 2 months of treatment are less likely to achieve successful treatment outcomes. On the other hand, patients with TB who gain $5 \%$ of their body weight within the first 2 months of treatment had smaller risk of unsuccessful treatment. $^{7}$

Patients with delayed sputum conversion during the intensive phases of TB treatment are associated with treatment failure. Patients with higher proportion of bacillary load at initial TB treatment are not able to convert sputum compared with patients with lower proportion of bacillary load at initial treatment. $^{8}$ Identifying the relationship between body weight and sputum status will help investigators to consider body weight as a biomarker for monitoring TB treatment outcomes in lower income settings.

Using longitudinal data analysis, trends of variables among study subjects can be measured. ${ }^{9}$ In resource-limited settings, joint modelling of body weight and sputum status in time courses was rarely scrutinised. Therefore, the objectives of this study were to 
describe the association between change in body weight and sputum smear conversion and to identify the factors linked with change in body weight and sputum conversion in Jimma University Specialized Hospital (JUSH), Southwest Ethiopia.

\section{MATERIALS AND METHODS Joint modelling}

Joint modelling enables researchers to study several outcome variables simultaneously. Often, these outcome variables are mixed in type. Variables in longitudinal modelling can be continuous, binary, ordinal, survival and/or missing. Applying separate model (by taking one as explanatory variable) is not efficient to see the association between two longitudinal data. Furthermore, joint modelling of variables addresses additional relevant research hypothesis. To identify whether a new treatment improves more than one treatment outcomes over time, joint modelling is appropriate. ${ }^{10}$

\section{Study design}

We conducted a retrospective follow-up study between September 2011 and July 2013 at the JUSH TB clinic in Southwest Ethiopia.

\section{Study participants}

Participants included patients with TB who were enrolled in direct observation TB treatment during the study period.

\section{Study setting}

A study was conducted at the JUSH TB clinic in Southwest Ethiopia. On average a total of 150 patients with TB were enrolled to direct observation therapy per year. Diagnosis of active TB was based on sputum microscopy, X-ray, histopathology, culture or/and molecular techniques. Once patients were diagnosed with active TB, they are started on TB treatment accordingly. ${ }^{11}$

\section{Sample size}

All patients with TB who were enrolled at the JUSH TB clinic between 2011 and 2013 were included in the analysis. A total of 450 patients with TB were included in the follow-up.

\section{Data collection}

Data were extracted from patient cards using case report forms. Patient cards with complete list of the required variables were included in the analysis. A baseline survey of demographic and clinical variables (age, sex, residence, type of TB, HIV status, dose of anti-TB drug, body weight and sputum status) was conducted at the first visit of direct observation TB treatment. The above-mentioned study variables were rechecked when patients come to the TB clinic for drug picking. During the intensive phase, which was the first 2 months of TB treatment, patients came to the clinic for direct observation treatment on a daily basis. During the continuous phase, which was between the third and sixth months of treatment, patients collected anti-TB drugs from the clinic every month. Body weight was measured in kilogram during the initiation of ТB treatment as a baseline and repeatedly measured every 2 months. Sputum status was examined at the end of the second, fifth and sixth months of treatment. The following predictor variables were included in the analysis: sex, age, type of TB, HIV status, residence, and time and dose of anti-TB drug. The standard dose of anti-TB drugs given to each patient is based on Ethiopia TB treatment guideline. The dose of a single anti-TB tablet is different based on anti-TB drug combinations: for instance, rifampicin, isoniazid, pyrazinamide and ethambutol $(\mathrm{R} / \mathrm{H} / \mathrm{Z} / \mathrm{E}), 1$ tablet $=150 / 75 / 400 / 275 \mathrm{mg} ; \mathrm{R} / \mathrm{H}, 1$ tablet $=150 / 75 \mathrm{mg}$; and $\mathrm{E} / \mathrm{H}, 1$ tablet $=400 / 150 \mathrm{mg} .{ }^{11}$ The outcome variables of the study were body weight and sputum conversion.

\section{Data analysis}

A separate model was computed to measure body weight as well as sputum status. Linear mixed model (LMM) was used to analyse body weight. Covariates such as age, sex, categories of TB, dose of anti-TB drug, time and HIV status were added in the LMM as predictors for body weight. To analyse sputum status, generalised linear mixed model (GLMM) was computed. Covariates such as age, sex, categories of TB, dose of anti-TB drug, time and HIV status were included in the GLMM.

Joint model was used to analyse body weight and sputum status. Separate models were fitted for the two outcomes (body weight and sputum status) together by assuming $\rho=0$. The joint model investigated the link between change in body weight and change in sputum status, that is, association of changes.

The likelihood comparison showed that a more convincing improvement in model fit was observed from the result of multivariate settings compared with the result of independent settings. Joint modelling of the two outcomes (body weight and sputum conversion together) was significantly better than two separate models $\left(\chi^{2}\right.$ $=116.13, \mathrm{df}=4, \mathrm{p}<0.0001$ ).

\section{Patient and public involvement}

No patient or the public was involved in the development of research question and design of the study. The results of this research will be disseminated to stakeholders such as the Regional Health Office and Jimma University after being published in a scientific journal.

\section{RESULTS}

At the end of the follow-up, 3.4\% of the patients were lost to follow-up (1.1\% died, $1.3 \%$ transferred out and $1 \%$ dropped out). The mean age of patients with TB was 29.47 years ( $\mathrm{SD}=11.8$ years). Likewise, the mean body weight was $48.29 \mathrm{~kg}(\mathrm{SD}=7.18 \mathrm{~kg})$. Table 1 presents the sociodemographic and clinical factors of patients with TB. Majority ( $82 \%$ ) of them were between the ages of 18 
Table 1 Baseline sociodemographic and clinical factors of patients with tuberculosis (TB) in Jimma University Specialized Hospital, Southwest Ethiopia

\begin{tabular}{|c|c|c|}
\hline Variables & Frequency & $\%$ \\
\hline \multicolumn{3}{|l|}{ Age (years) } \\
\hline $18-40$ & 368 & 81.8 \\
\hline $41-60$ & 62 & 13.8 \\
\hline $61+$ & 20 & 4.4 \\
\hline \multicolumn{3}{|l|}{ Sex } \\
\hline Female & 178 & 39.6 \\
\hline Male & 272 & 60.4 \\
\hline \multicolumn{3}{|l|}{ Residence } \\
\hline Rural & 198 & 44.0 \\
\hline Urban & 252 & 56.0 \\
\hline \multicolumn{3}{|l|}{ Type of TB } \\
\hline Extrapulmonary TB & 214 & 47.6 \\
\hline Pulmonary TB & 236 & 52.4 \\
\hline \multicolumn{3}{|l|}{ HIV status } \\
\hline Positive & 76 & 16.9 \\
\hline Negative & 374 & 83.1 \\
\hline \multicolumn{3}{|l|}{ Dose of anti-TB drug } \\
\hline Two tablets & 55 & 12.2 \\
\hline Three tablets & 338 & 75.1 \\
\hline Four tablets & 57 & 12.7 \\
\hline \multicolumn{3}{|l|}{ Sputum status } \\
\hline Smear-positive & 163 & 36.2 \\
\hline Non-smear-positive & 287 & 63.8 \\
\hline \multicolumn{3}{|l|}{ Body weight (kg) } \\
\hline 29-39 & 55 & 12.2 \\
\hline $40-54$ & 338 & 75.1 \\
\hline $55+$ & 57 & 12.7 \\
\hline
\end{tabular}

and 40 years. The prevalence of HIV among patients with TB was $16 \%$.

\section{LMM for body weight with linear time effect}

Table 2 presents the association between predictor variables and body weight. The study variables sex, age, type of TB, HIV status and dose of anti-TB drug were significantly associated with body weight.

\section{Separate analysis of binary longitudinal outcome (sputum conversion)}

Table 3 presents the association between predictor variables and sputum status. The covariates age, dose, type of TB and time had significant effects on sputum status of the patients. Old age was associated with higher rates of positive sputum status.

\section{Joint model of body weight and sputum conversion}

Using joint model, the association of changes between the random slope for body weight and the random slope
Table 2 Predictors for body weight in patients with tuberculosis (TB) in Jimma University Specialized Hospital, Southwest Ethiopia

\begin{tabular}{lllll}
\hline & \multicolumn{2}{l}{ Joint model } & & \multicolumn{2}{l}{ Separate model } \\
\cline { 2 - 3 } \cline { 5 - 5 } Variables & $\begin{array}{l}\text { Estimates } \\
\text { (SE) }\end{array}$ & P values & $\begin{array}{l}\text { Estimate } \\
\text { (SE) }\end{array}$ & P values \\
\hline Sex & $6.17(0.70)$ & $<0.001$ & $6.16(0.71)$ & $<0.001$ \\
\hline Age & $0.18(0.01)$ & 0.016 & $0.18(0.01)$ & $<0.001$ \\
TB type & $0.14(0.01)$ & $<0.001$ & $0.13(0.07)$ & 0.007 \\
\hline HIV status & $0.79(0.06)$ & $<0.001$ & $0.79(0.07)$ & 0.005 \\
\hline $\begin{array}{l}\text { Dose of anti- } \\
\text { TB drug }\end{array}$ & $3.81(0.27)$ & 0.014 & $3.72(0.43)$ & $<0.001$ \\
\hline Time & $1.88(0.04)$ & $<0.001$ & $1.78(0.49)$ & 0.002 \\
\hline $\begin{array}{l}\text { Sex with time } \\
\text { Age with time }\end{array}$ & $-0.17(0.07)$ & 0.004 & $-0.18(0.19)$ & 0.008 \\
\hline $\begin{array}{l}\text { TB type with } \\
\text { time }\end{array}$ & $-0.21(0.01)$ & $<0.001$ & $0.01(0.04)$ & 0.009 \\
\hline $\begin{array}{l}\text { HIV status } \\
\text { with time }\end{array}$ & $-0.30(0.21)$ & 0.013 & $-0.21(0.18)$ & 0.001 \\
\hline $\begin{array}{l}\text { Dose of anti- } \\
\text { TB drug with }\end{array}$ & $-0.26(0.13)$ & 0.001 & $-0.25(0.13)$ & 0.002 \\
time & & & & \\
\hline
\end{tabular}

$\alpha=0.05$, $p$ value less than 0.05 is statistically significant.

for sputum conversion was -0.698 ( $\mathrm{SE}=0.134, \mathrm{p}<0.001)$. The negative value indicated inverse association between change in body weight and change in sputum conversion.

\section{DISCUSSION}

This study described the link between body weight and sputum conversion in patients with TB. In addition, the study identified predictors for body weight and sputum conversion among patients who were on TB treatment.

Table 3 Predictors for sputum conversion in patients with tuberculosis (TB) in Jimma University Specialized Hospital, Southwest Ethiopia

\begin{tabular}{|c|c|c|c|c|}
\hline \multirow[b]{2}{*}{ Variables } & \multicolumn{2}{|l|}{ Joint model } & \multicolumn{2}{|c|}{ Separate model } \\
\hline & $\begin{array}{l}\text { Estimates } \\
\text { (SE) }\end{array}$ & $P$ values & Variables & $\begin{array}{l}\text { Estimates } \\
\text { (SE) }\end{array}$ \\
\hline Age & $0.03(0.02)$ & 0.007 & $0.01(0.25)$ & $<0.001$ \\
\hline TB type & $-2.85(0.02)$ & $<0.001$ & $-2.60(0.18)$ & 0.005 \\
\hline $\begin{array}{l}\text { Dose of anti- } \\
\text { TB drug }\end{array}$ & $-0.19(0.04)$ & 0.01 & $-0.17(0.74)$ & 0.006 \\
\hline Time & $-2.55(0.04)$ & 0.001 & $-2.02(0.01)$ & 0.008 \\
\hline $\begin{array}{l}\text { Age with } \\
\text { time }\end{array}$ & $0.09(0.21)$ & 0.005 & $0.08(0.31)$ & $<0.001$ \\
\hline $\begin{array}{l}\text { TB type with } \\
\text { time }\end{array}$ & $2.49(0.02)$ & $<0.001$ & $1.32(0.21)$ & 0.002 \\
\hline $\begin{array}{l}\text { Dose of anti- } \\
\text { TB drug with } \\
\text { time }\end{array}$ & $0.06(0.12)$ & 0.04 & $0.01(0.13)$ & 0.003 \\
\hline
\end{tabular}

$\alpha=0.05$, $p$ value less than 0.05 is statistically significant. 
These findings will have an important impact on public health particularly in lower incomes settings, where TB burden is overwhelming the already limited health system.

Our study found a strong inverse association between change in body weight and change in sputum conversion. Similarly, a study conducted in Peru identified that patients with pulmonary TB who gained less than $5 \%$ their body weight were associated with lack of sputum conversion. ${ }^{12}$ Furthermore, a study in Indonesia reaffirmed that body weight increment and sputum culture conversion were inversely related. ${ }^{13}$

Ethiopia TB treatment guideline recommends regular sputum status assessment as an indicator of treatment response. ${ }^{12}$ In this study we found a strong correlation between body weight and sputum status. A study finding identified that body weight was associated with TB treatment outcomes. Patients with loss of body weight were associated with poor treatment outcomes, such as drug resistance to TB, treatment failure, relapse and clinical deterioration. $^{8}$

Patients with TB with low level of weight gain require intensified follow-up and management. On the other hand, patients with good treatment outcomes were linked to weight gain. ${ }^{14}$ This implies weight gain could be a predictor of good treatment outcomes.

The study variables of this research-sex, age, type of TB, HIV status, dose of anti-TB drug and length of enrolment to TB treatment-were significantly associated with change in body weight. The association of body weight with the covariates sex, dose of anti-TB drug and age was consistent with other studies. ${ }^{15-17}$

In this study, patients with smear-positive pulmonary TB had better weight gain than patients with TB who were not pulmonary-positive. Consistent with our findings, a study identifies that patients with smear-positive TB were associated with better weight gain than patients with non-smear-positive TB. ${ }^{18}$ Smear-negative TB, extrapulmonary $\mathrm{TB}$ and disseminated $\mathrm{TB}$ were more likely linked to other comorbidities such as HIV infection than smear-positive TB. ${ }^{19}$ Patients with non-smear-positive TB who did not gain body weight as patients with smear-positive TB might link with HIV wasting syndrome. ${ }^{20}$ Furthermore, our study found that HIV-negative patients with TB gain higher body weight than HIV-positive patients with TB.

In this study younger age adult patients with TB were associated with higher weight gain than older age adult patients with TB. Similarly, a study identified higher rates of weight gain among younger adult patients with TB (younger than 40 years) than those who were 40 years and older. $^{21} \mathrm{~A}$ research identified that unintentional weight loss is more common in elderly patients. ${ }^{17}$ Unintentional weight loss because of common geriatric disorders such as depression, cancer, cardiac disorder and benign gastrointestinal disorder is observed. ${ }^{22}$ To enhance successful TB treatment outcomes among the elderly, focused body weight monitoring and handlings of weight loss should be emphasised.
Loss of appetite along with nausea is a common sign of TB. Patients diagnosed with TB is associated with wasting, which is characterised by depletion of whole-body lean and fat tissue. ${ }^{20}$ This study showed that patients with $\mathrm{TB}$ on longer duration of treatment were linked with increased body weight. ${ }^{11}$ Consistent with our findings, a study revealed that the body weight of patients with TB increased in a linear fashion throughout the course of treatment. ${ }^{18}$ Often, patients with TB with successful treatment outcomes have reduced symptoms. ${ }^{23}$ However, further studies that will investigate the mechanisms of weight increment during TB treatment are warranted.

The study variables age, type of $\mathrm{TB}$, dose of anti-TB drug and length of enrolment to TB treatment were significantly associated with change in sputum status. Even though patients with $\mathrm{TB}$ were taking similar anti-TB treatment, sputum conversion was not the same among all patients with TB. This could be due to differences in biomedical profile, TB treatment response, dietary and social factors. ${ }^{24-27}$

Among patients with TB who were taking anti-TB drugs, delayed sputum conversion was associated with old age. ${ }^{28} 29$ A study identified age-related decline in $\mathrm{T}$ cell immune responses, which was linked to increased risk of TB infection. Furthermore, other factors such as age-related diseases, including malignancy, diabetes mellitus, poor nutrition and immunosuppression, contribute to increased risk of TB in the old age segment of the population. Similarly, studies reaffirmed that, compared with young adults, elders were less effective in preventing and/or getting rid of TB bacilli. ${ }^{30} 31$

Ethiopia TB treatment guideline recommends fixeddose combination therapies. In our study setting, fixeddose combination therapies were given. During the therapy, anti-TB drug doses were calculated based on the body weight of the patients. ${ }^{11}$ In this study the dose of anti-TB drug was significantly associated with sputum conversion. Fixed-dose combinations of higher dose groups were more likely associated with sputum conversion (from smear-positive sputum to smear-negative sputum) than fixed-dose combinations of lower dose groups. On the other hand, lower weight patients with TB who were taking lower doses of anti-TB drugs could be sicker than patients with higher body weight who were taking higher doses of anti-TB drugs. In terms of treatment outcomes, sicker patients with TB might have worse outcomes than less sick patients. Further prospective study that will control more potential confounding variables and is able to establish temporal sequence is warranted.

The length of enrolment to TB treatment was associated with sputum conversion. As the length of time on TB treatment increased, the probability of sputum conversion was increased. Seventy per cent of patients with TB had sputum conversion at the first month of treatment, while $90 \%$ had sputum conversion at the second month of treatment. ${ }^{32}$ Similarly, our study identified an association between length of time on TB treatment and sputum conversion. Another study investigated that Mycobacterium bacilli dose was associated with the rate of sputum 
conversion. ${ }^{33}$ Lack of sputum conversion was linked with high bacterial load. ${ }^{34}$ As the length of time on TB treatment increased, mycobacterial load in human host was reduced.$^{35}$ In general, the findings of this research can be extrapolated to patients with TB in lower income settings who are on direct observations TB treatment.

\section{Limitations of the study}

While sputum microscopy is a gold standard diagnostic tool for pulmonary $\mathrm{TB}$, it may lack sensitivity and specificity. ${ }^{36}$ As we conduct this retrospective follow-up study, predictors could not establish temporal relationship. Therefore, causation of factor cannot be inferred. One of the limitations of joint modelling is calculation challenge, which requires to integrate the distributions of the random effects even with fairly simple circumstances, that is, a single longitudinal outcome and a single survival event. ${ }^{37}$

\section{CONCLUSIONS}

Among patients with TB who were on anti-TB treatment, increase in body weight and positive sputum status were inversely related over time. TB prevention and control strategies should give emphasis on factors such as female sex, older age, non-pulmonary positive type of TB, HIV positive, lower dose of anti-TB drug and length of enrolment to $\mathrm{TB}$ treatment during monitoring of trends in body weight and sputum status.

Acknowledgements The authors acknowledge the JUSH TB clinic. The authors would like to send their gratitude to data collectors.

Contributors All authors (MF, ZM and YMA) conceived and designed the experiments, performed the experiments, analysed the data, contributed reagents/ materials/analysis tools, and wrote the paper.

Funding The authors have not declared a specific grant for this research from any funding agency in the public, commercial or not-for-profit sectors.

Competing interests None declared.

Patient consent Not required.

Ethics approval Ethical approval was obtained from Jimma University Science College Research Ethics Committee. Written permission to conduct the study was granted by the JUSH. This study was a retrospective follow-up; patient records were anonymised and de-identified prior to analysis. Patient informed consent was not required as only anonymous and operational monitoring data were collected and analysed.

Provenance and peer review Not commissioned; externally peer reviewed.

Data sharing statement No additional data are available.

Open access This is an open access article distributed in accordance with the Creative Commons Attribution Non Commercial (CC BY-NC 4.0) license, which permits others to distribute, remix, adapt, build upon this work non-commercially, and license their derivative works on different terms, provided the original work is properly cited, appropriate credit is given, any changes made indicated, and the use is non-commercial. See: http://creativecommons.org/licenses/by-nc/4.0/.

\section{REFERENCES}

1. World Health Organization. Global Tuberculosis Report 2016: WHO, 2017.

2. Park $\mathrm{HO}$, Kim SH, Moon SH, et al. Association between body mass index and sputum culture conversion among South Korean patients with multidrug resistant tuberculosis in a tuberculosis referral hospital. Infect Chemother 2016;48:317-23.
3. Kamal SM, Hassan $\mathrm{CH}$, Alam GM. Dual burden of underweight and overweight among women in Bangladesh: patterns, prevalence, and sociodemographic correlates. J Health Popul Nutr 2015;33:92-105.

4. Rohini K, Bhat S, Srikumar PS, et al. Serum PCT and its relation to body weight gain in pulmonary tuberculosis. Indian J Clin Biochem 2015;30:329-33.

5. Chandrasekaran P, Saravanan N, Bethunaickan R, et al. Malnutrition: modulator of immune responses in tuberculosis. Front Immunol 2017;8:1316.

6. Miyata S, Tanaka M, Ihaku D. The prognostic significance of nutritional status using malnutrition universal screening tool in patients with pulmonary tuberculosis. Nutr J 2013;12:42.

7. Hoa NB, Lauritsen JM, Rieder HL. Changes in body weight and tuberculosis treatment outcome in Viet Nam. Int $J$ Tuberc Lung Dis 2013;17:61-6.

8. Djouma FN, Noubom M, Ateudjieu J, et al. Delay in sputum smear conversion and outcomes of smear-positive tuberculosis patients: a retrospective cohort study in Bafoussam, Cameroon. BMC Infect Dis 2015;15:139.

9. Gibbons RD, Hedeker D, DuToit S. Advances in analysis of longitudinal data. Annu Rev Clin Psychol 2010;6:79-107.

10. Wang P, Shen W, Boye ME. Joint modeling of longitudinal outcomes and survival using latent growth modeling approach in a mesothelioma trial. Health Serv Outcomes Res Methodol 2012;12:182-99.

11. Federal Ministry of Health Ethiopia. Guide lines for clinical and program management of TB, TB/HIV and leprosy: Ministry of Health, 2013.

12. Krapp F, Véliz JC, Cornejo E, et al. Bodyweight gain to predict treatment outcome in patients with pulmonary tuberculosis in Peru. Int J Tuberc Lung Dis 2008;12:1153-9.

13. Putri FA, Burhan E, Nawas $A$, et al. Body mass index predictive of sputum culture conversion among MDR-TB patients in Indonesia. Int $J$ Tuberc Lung Dis 2014;18:564-70.

14. Bernabe-Ortiz A, Carcamo CP, Sanchez JF, et al. Weight variation over time and its association with tuberculosis treatment outcome: a longitudinal analysis. PLoS One 2011;6:e18474.

15. Amare H, Gelaw A, Anagaw B, et al. Smear positive pulmonary tuberculosis among diabetic patients at the Dessie referral hospital, Northeast Ethiopia. Infect Dis Poverty 2013;2:6.

16. Sreeramareddy CT, Panduru KV, Verma SC, et al. Comparison of pulmonary and extrapulmonary tuberculosis in Nepal- a hospitalbased retrospective study. BMC Infect Dis 2008;8:8.

17. Moriguti JC, Moriguti EK, Ferriolli E, et al. Involuntary weight loss in elderly individuals: assessment and treatment. Sao Paulo Med J 2001;119:72-7.

18. Phan MN, Guy ES, Nickson RN, et al. Predictors and patterns of weight gain during treatment for tuberculosis in the United States of America. Int $J$ Infect Dis 2016;53:1-5.

19. Golden MP, Vikram HR. Extrapulmonary tuberculosis: an overview. Am Fam Physician 2005;72:1761-8.

20. Paton NI, Ng YM. Body composition studies in patients with wasting associated with tuberculosis. Nutrition 2006;22:245-51.

21. Vasantha M, Gopi PG, Subramani R. Weight gain in patients with tuberculosis treated under directly observed treatment short-course (DOTS). Indian J Tuberc 2009;56:5-9.

22. Huffman GB. Evaluating and treating unintentional weight loss in the elderly. Am Fam Physician 2002;65:640-50.

23. Sia IG, Wieland ML. Current concepts in the management of tuberculosis. Mayo Clin Proc 2011;86:348-61.

24. Horne DJ, Royce SE, Gooze L, et al. Sputum monitoring during tuberculosis treatment for predicting outcome: systematic review and meta-analysis. Lancet Infect Dis 2010;10:387-94.

25. Pajankar S, Khandekar R, Al Amri MA, et al. Factors influencing sputum smear conversion at one and two months of tuberculosis treatment. Oman Med J 2008;23:263-8.

26. Parikh R, Nataraj G, Kanade S, et al. Time to sputum conversion in smear positive pulmonary TB patients on category I DOTS and factors delaying it. J Assoc Physicians India 2012;60:22-6.

27. Banu Rekha VV, Balasubramanian R, Swaminathan S, et al. Sputum conversion at the end of intensive phase of Category-1 regimen in the treatment of pulmonary tuberculosis patients with diabetes mellitus or HIV infection: An analysis of risk factors. Indian J Med Res 2007;126:452-8.

28. Gunda DW, Nkandala I, Kavishe GA, et al. Prevalence and risk factors of delayed sputum conversion among patients treated for smear positive PTB in Northwestern rural Tanzania: a retrospective cohort study. J Trop Med 2017;2017:1-5.

29. Mlotshwa M, Abraham N, Beery M, et al. Risk factors for tuberculosis smear non-conversion in Eden district, Western Cape, South 
Africa, 2007-2013: a retrospective cohort study. BMC Infect Dis 2016;16:365.

30. Rajagopalan S. Tuberculosis and aging: a global health problem. Clin Infect Dis 2001:33:1034-9.

31. Prasad P, Gounder S, Varman S, et al. Sputum smear conversion and treatment outcomes for tuberculosis patients with and without diabetes in Fiji. Public Health Action 2014;4:159-63.

32. Bawri S, Ali S, Phukan C, et al. A study of sputum conversion in new smear positive pulmonary tuberculosis cases at the monthly intervals of 1,2 \& 3 month under directly observed treatment, short course (dots) regimen. Lung India 2008;25:118-23.

33. Azarkar Z, Sharifzadeh G, Ebrahimzadeh A, et al. Time to sputum smear conversion in smear-positive pulmonary tuberculosis patients and factors for delayed conversion. Iran J Med Sci 2016;41:44-7.
34. Olaru ID, Heyckendorf J, Grossmann S, et al. Time to culture positivity and sputum smear microscopy during tuberculosis therapy. PLoS One 2014;9:e106075.

35. Via LE, England K, Weiner DM, et al. A sterilizing tuberculosis treatment regimen is associated with faster clearance of bacteria in cavitary lesions in marmosets. Antimicrob Agents Chemother 2015;59:4181-9.

36. Singhal R, Myneedu VP. Microscopy as a diagnostic tool in pulmonary tuberculosis. Int J Mycobacteriol 2015;4:1-6.

37. Lawrence Gould A, Boye ME, Crowther MJ, et al. Joint modeling of survival and longitudinal non-survival data: current methods and issues. Report of the DIA Bayesian joint modeling working group. Stat Med 2015;34:2181-95. 